\title{
The decongestive lymphatic therapy in the massive primary lower limb lymphedema treatment
}

\author{
Katarzyna Drozdz, Angelika Chachaj, Andrzej Szuba \\ Division of Angiology, Wroclaw Medical University, Poland \\ Department of Internal Medicine, $4^{\text {th }}$ Military Hospital, Wroclaw, Poland
}

\begin{abstract}
The decongestive lymphatic therapy is recommended by the International Society of Lymphology, the International Union of Phlebology and the International Lymphoedema Framework as the conservative treatment of choice in the lymphedema patients. This method enables effective treatment even in patients with difficult and complicated lymphedema.

We present a case of a young man with a massive, primary right lower limb lymphedema, effectively treated with the DLT.
\end{abstract}

Key words: decongestive lymphatic therapy, lymphedema, bandaging, garments, manual lymphatic drainage

Acta Angiol 2017; 23, 3: 130-134

\section{Introduction}

The decongestive lymphatic therapy (DLT) is recommended by the International Society of Lymphology (ISL), the International Union of Phlebology (UIP) and the International Lymphoedema Framework (ILF) as a first step in the primary lymphedema treatment. The DLT consists of manual lymphatic drainage (MLD), compression multilayer short-stretch bandaging, garments, meticulous skin care and decongestive exercises. Additionally, unceasing patient education is also very important. At least 6 months of the DLT should precede all surgical treatment of a chronic lymphedema. Furthermore, postoperative DLT is always necessary to maintain the surgical achievements [I]. Patient's education is critical to sustained expected outcomes.

We present a case of a young man with a massive, primary right lower limb lymphedema, effectively treated with the DLT.

\section{Case study}

44-year old man with massive primary right lower extremity lymphedema, obesity and hypertension was admitted to the Department of the Internal Medicine of the $4^{\text {th }}$ Military Hospital in Wroclaw, Poland. The lymphedema appeared in a patient 30 years of age and gradually increased. The patient has been repeatedly hospitalized in the different medical centers due to edema and recurrent skin infections with no significant clinical improvement.

At the time of the current admission to the hospital the patient was unable to walk by himself. The physical examination revealed: obesity [body mass index (BMI) - 78], the maximum circumference of the right thigh and calf were respectively $132 \mathrm{~cm}$ and $125 \mathrm{~cm}$, the skin in the area of edema was thickened, with numerous deep folds of thick and hard skin, the right heel deep ulcer was present (Figs. I-4). The blood pressure was elevated (I70/I00 mm Hg). 


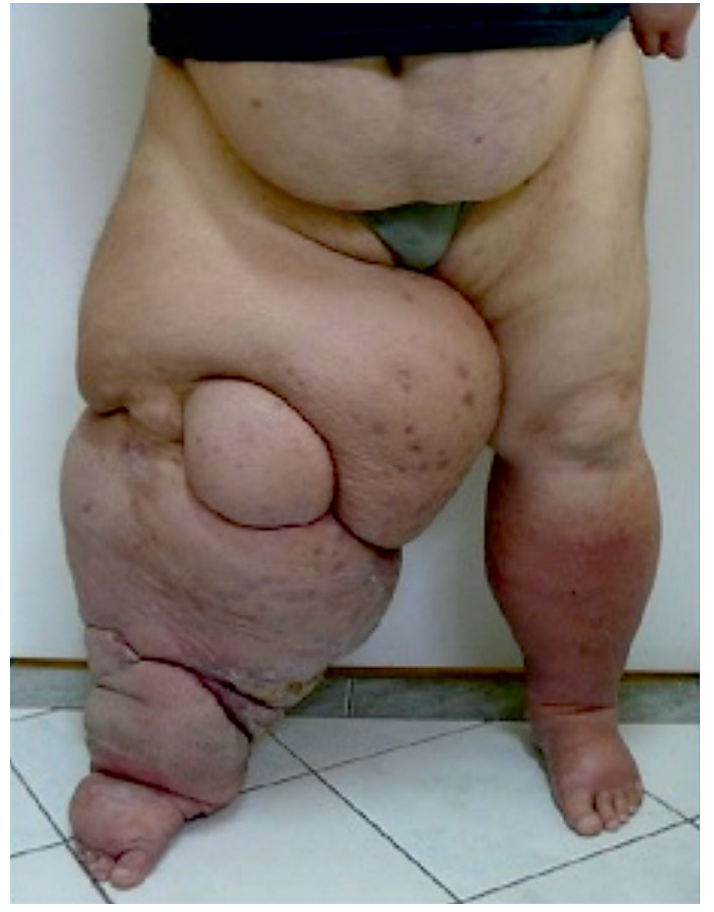

Figure I. The right lower limb lymphedema before the treatment (front view)

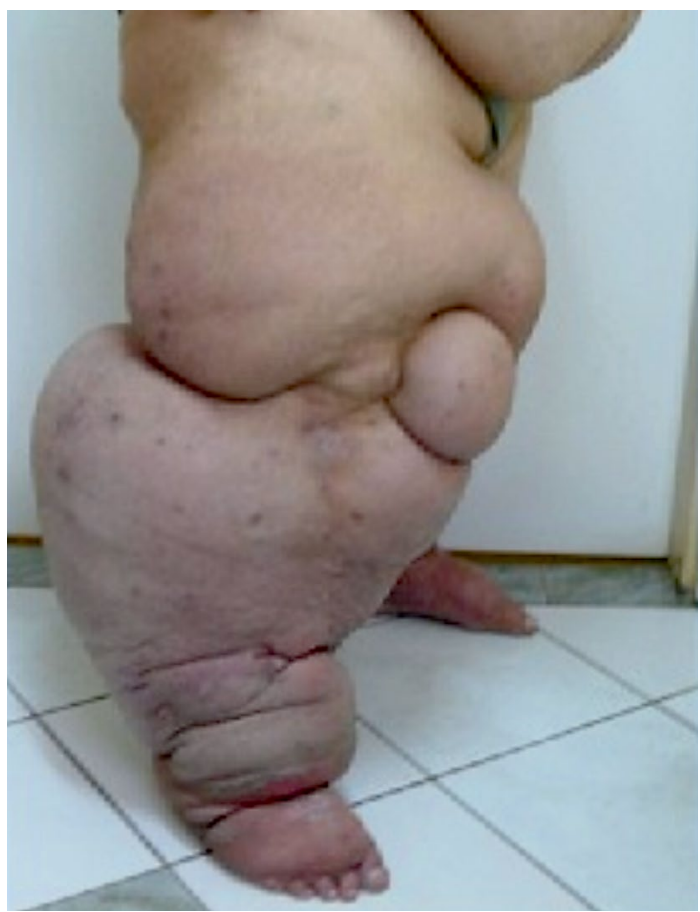

Figure 3. The right lower limb lymphedema before the treatment (side view)

The patient underwent routine diagnostics. The blood tests showed anemia and increased inflammatory markers. The Doppler ultrasound excluded lower limbs

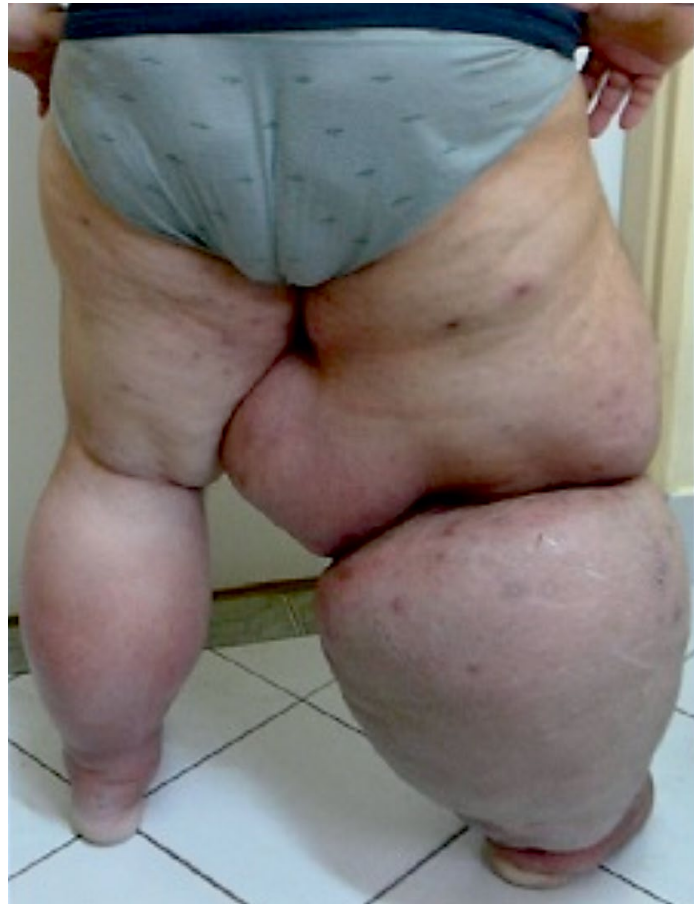

Figure 2. The right lower limb lymphedema before the treatment (rear view)

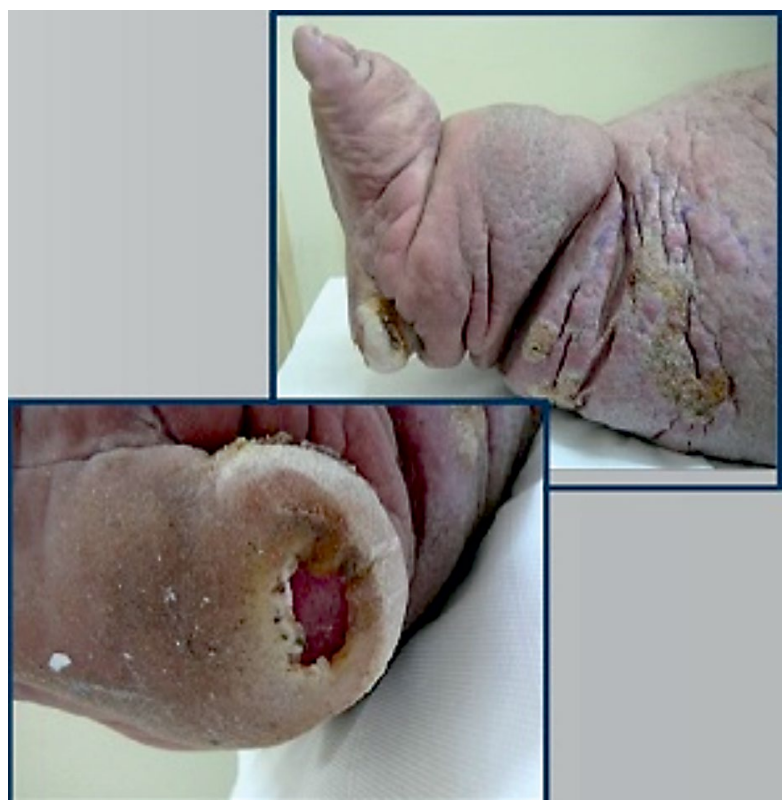

Figure 4. The right heel deep ulcer before the treatment

deep venous thrombosis. The abdominal and pelvis MRI scans have shown no significant pathology. The lymphoscintigraphy confirmed the primary right lower limb lymphedema. The ABPM (ambulatory blood pressure monitoring) showed poor control of blood pressure. A moderate sleep apnea syndrome was confirmed with polysomnography. 


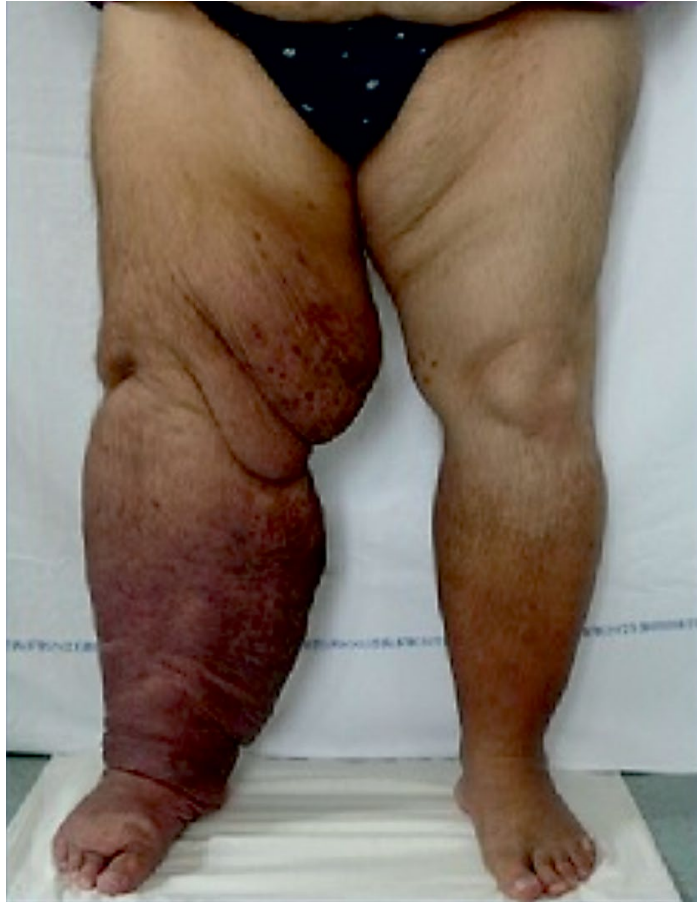

Figure 5. The right lower limb lymphedema after twelve weeks of the treatment (front view)

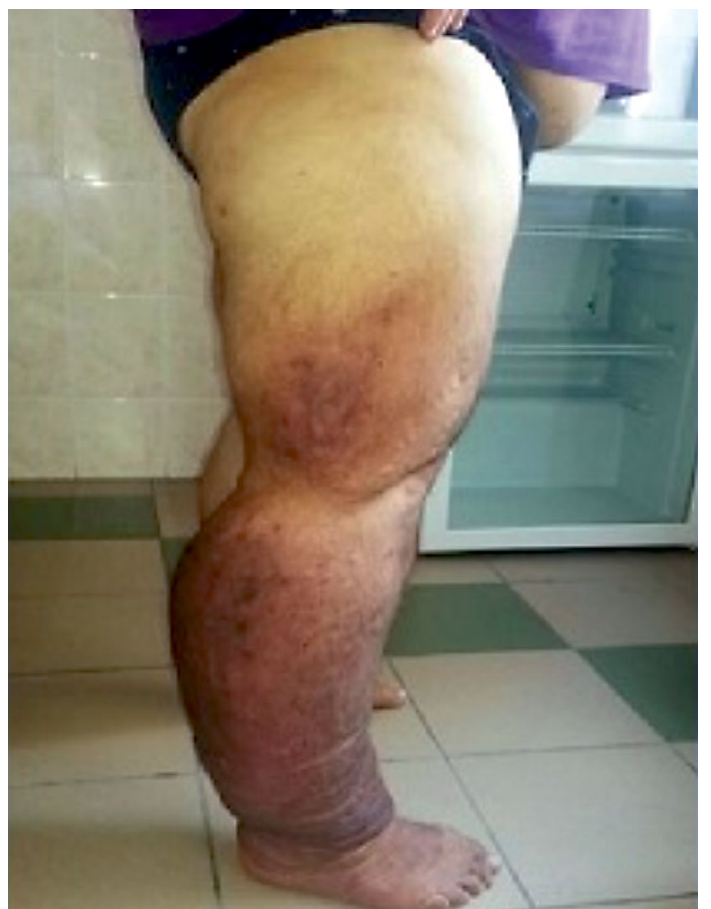

Figure 7. The right lower limb lymphedema after twelve weeks of the treatment (side view)

The DLT five times a week, including: MLD, SIPC (sequential intermittent pneumatic compression), multilayer short-stretch compression bandaging and decongestive exercises was applied. Additionally, antibiotic

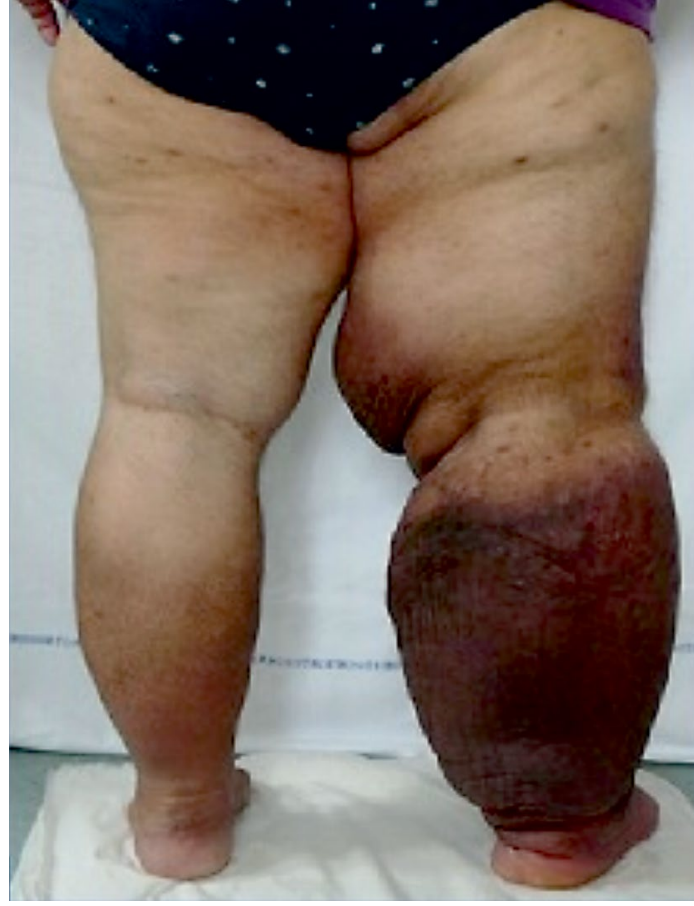

Figure 6. The right lower limb lymphedema after twelve weeks of the treatment (rear view)

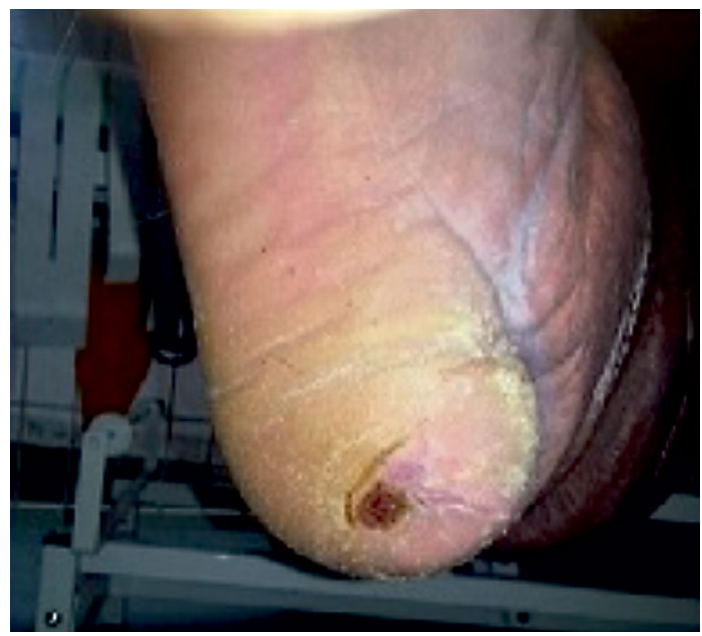

Figure 8. The right heel deep ulcer after twelve weeks of the treatment

therapy and a heel ulcer dressing was started. After two cycles of the DLT (lasting eight weeks, respectively, and 4 weeks) significant edema reduction was achieved. The maximum thigh circumference was reduced from $132 \mathrm{~cm}$ to $83 \mathrm{~cm}$, the maximum circumference of the calf was reduced from $125 \mathrm{~cm}$ to $79 \mathrm{~cm}$ and weight fallen from $213 \mathrm{~kg}$ to $156 \mathrm{~kg}$. The volume of the right lower extremity was reduced by 39 liters and the sores of the heel were healed completely (Figs. 5-8). The patient was able to walk independently. 


\section{Discussion}

The successful management of lymphedema requires multi-faceted approach. The DLT consists of two phases. The first is to reduce swelling, and the second is to maintain the effect of the first phase.

The first phase of intensive management for the I-4 weeks in our center involves skin care, remedial exercise, MLD, SIPC and short-stretch multilayer lymphedema bandaging.

The greatest reduction of the limb volume is achieved usually within the first week of therapy. The therapy is applied daily, 7 days per week, and continue until complete edema reduction or a volumetric plateau is established [ $[, 2]$.

The second phase consists of long-term management strategies to gain control of the condition involving skin care, regular exercise, the use of compression garments (tailored flat knitted garments), self management (e.g. compression bandage or velcro-devices and/or self massage). This phase requires life-long commitment and the interruption of compression therapy causes usually rapid recurrence of edema [I-3].

The most important component of the DLT is multilayer bandaging with or without SIPC $[1,2,4,5]$. The type and level of bandaging is still under evaluation [3]. Traditional approaches to multi-layer lymphedema bandaging use inelastic bandages over padding or foam layers [2]. Bandages changed daily should not be applied with the same high pressure compared to bandages changed once or twice weekly. The optimal pressure range for reducing edema, corresponding to a pressure range around $30 \mathrm{~mm} \mathrm{Hg}$ for the upper and $50-60 \mathrm{~mm} \mathrm{Hg}$ for the lower extremity $[1,2,6]$. Higher pressures may be counterproductive. In some patients lower compression is appropriate and may help to improve compliance. The long term compression hosiery may be commenced after the pitting oedema is removed. The main contraindication for compression bandaging is critical ischemia and decompensated cardiac failure.

The useful treatment option for patients who have poor dexterity or limited strength and are unable to apply compression bandages are the compression wraps [7]. Those self-adjustable velcro-band devices, applied by lymphedema patients themselves may reduce edema more effectively than inelastic lymph bandages [8].

Both MLD and SIPC are used at each step in lymphedema treatment, especially in patients with low bandages or garments tolerance. However, there is no consensus on the frequency or treatment parameters for SIPC devices [9].

The skin infections are frequent problem lymphedema patients. Penicillin and cephalosporins are rec- ommended for dermatolymphangitiis prophylaxis in patients with lymphedema [I]. Our patients receive Benzetacil (Benzathini benzylpenicillinum) I.200.000 U, once every three weeks.

Various stages of lymphedema have different indications for surgical treatment. Regardless of the surgical method treatment (reconstructive surgery with microsurgical lympho-venous anastomoses, circumferential suction-assisted lipectomy), the DLT must precede them for at least 6 months. Furthermore, the DLT must be continued after this procedure [1, 10-12].

For patients with secondary lymphedema the DLT is also the primary method of treatment $[13,14]$.

\section{Conclusions}

The DLT in the majority of patients is the primary and the most effective method of lymphedema treatment, even in patients with difficult and complicated lymphedema.

\section{References}

I. Lee BB, Antignani PL, Baroncelli TA, et al. IUA-ISVI consensus for diagnosis guideline of chronic lymphedema of the limbs. Int Angiol. 2015; 34(4): 31 I-332, indexed in Pubmed: 24699525.

2. Moffatt $\mathrm{C}$, Partsch H, Schuren J, et al. Compression Therapy. A position document on compression bandaging. The International Lymphoedema Framework's. 2012.

3. Lamprou DAA, Damstra RJ, Partsch H. Prospective, randomized, controlled trial comparing a new two-component compression system with inelastic multicomponent compression bandages in the treatment of leg lymphedema. Dermatol Surg. 201 I; 37(7): 985-991, doi: 10.1 I I I/j.1524-4725.201 I.02002.x, indexed in Pubmed: 21575097.

4. Stout N, Partsch H, Szolnoky G, et al. Chronic edema of the lower extremities: international consensus recommendations for compression therapy clinical research trials. Int Angiol. 2012; 3I (4): 316-329, indexed in Pubmed: 22801397.

5. Partsch H, Stout N, Forner-Cordero I, et al. Clinical trials needed to evaluate compression therapy in breast cancer related lymphedema (BCRL). Proposals from an expert group. Int Angiol. 2010; 29(5): 442-453, indexed in Pubmed: 20924349.

6. Damstra RJ, Partsch H. Compression therapy in breast cancer-related lymphedema: A randomized, controlled comparative study of relation between volume and interface pressure changes. J Vasc Surg. 2009; 49(5): 1256-1263, doi: 10.1016/j. jvs.2008.12.018, indexed in Pubmed: 19394553.

7. Hampton S, Gray S. Selecting a compression wrap when treating lymphoedema. Br J Community Nurs. 2016; 21 (Suppl 10): S37-S39, doi: 10.12968/bjcn.2016.21.Sup 10.S37, indexed in Pubmed: 277I5I 45.

8. Partsch H, Damstra RJ, Mosti G. Dose finding for an optimal compression pressure to reduce chronic edema of the extremities. Int Angiol. 201 I; 30(6): 527-533, indexed in Pubmed: 22233613 . 
9. Feldman JL, Stout NL, Wanchai A, et al. Intermittent pneumatic compression therapy: a systematic review. Lymphology. 2012; 45(I): 13-25, indexed in Pubmed: 22768469.

10. Gloviczki P. Principles of surgical treatment of chronic lymphoedema. Int Angiol. 1999; 18(I): 42-46, indexed in Pubmed: 10392479.

II. Becker C. Autologous lymph node transfers. J Reconstr Microsurg. 2016; 32(I): 28-33, doi: 10.1055/s-0035-1563393, indexed in Pubmed: 26372688.

12. Lee BB, Kim YW, Kim DI, et al. Supplemental surgical treatment to end stage (stage IV-V) of chronic lymphedema. Int Angiol. 2008; 27(5): 389-395, indexed in Pubmed: I897470।.
13. Szuba A, Achalu R, Rockson SG. Decongestive lymphatic therapy for patients with breast carcinoma-associated lymphedema. A randomized, prospective study of a role for adjunctive intermittent pneumatic compression. Cancer. 2002; 95(I I): 2260-2267, doi: 10.1002/cncr.10976, indexed in Pubmed: 12436430 .

14. Szuba A, Cooke JP, Yousuf S, et al. Decongestive lymphatic therapy for patients with cancer-related or primary lymphedema. Am J Med. 2000; 109(4): 296-300, indexed in Pubmed: 10996580. 